\title{
The Consequences of Alcohol- Involved Sexual Victimization in Male and Female College Students
}

\author{
Ivy-Lee L. Kehayes and Amanda Hudson \\ Dalhousie University \\ Kara Thompson \\ St. Francis Xavier University \\ Christine Wekerle \\ McMaster University \\ Heather Stuart \\ Queen's University \\ Keith Dobson \\ University of Calgary \\ Terry Krupa \\ Queen's University
}

Ivy-Lee L. Kehayes and Amanda Hudson, Department of Psychology and Neuroscience, Dalhousie University, Halifax, Nova Scotia; Kara Thompson, Department of Psychology and Neuroscience, Dalhousie University, Halifax, Nova Scotia, and Department of Psychology, St. Francis Xavier University, Antigonish, Nova Scotia; Christine Wekerle, Department of Pediatrics, McMaster University, Hamilton, Ontario; Heather Stuart, Department of Public Health Sciences, Queen's University, Kingston, Ontario; Keith S. Dobson, Department of Psychology, University of Calgary, Calgary, Alberta; Terry Krupa, School of Rehabilitation Therapy, Queen's University, Kingston, Ontario; Sherry H. Stewart, Departments of Psychiatry, and Psychology and Neuroscience, Dalhousie University, Halifax, Nova Scotia.

Amanda Hudson, Mental Health and Addictions Program Lead, Health PEI, Charlottetown, Prince Edward Island; Kara Thompson Department of Psychology, St. Francis Xavier University, Antigonish, Nova Scotia.

The Caring Campus Project was funded by Movember Canada (Grant \# 35361), Stuart H, Chen S-P, Krupa T, Dobson K, Stewart S, and Teehan, M. Annie Chinneck, Parnell Davis-MacNevin, Craig Moore, and Jennifer Swansburg are also thanked for their research assistance.

Correspondence concerning this article should be addressed to Ivy-Lee L. Kehayes, Department of Psychology and Neuroscience, Dalhousie University, Life Sciences Centre, 1355 Oxford Street, P.O. Box 15000, Halifax, Nova Scotia, Canada, B3H 4R2. Email: ivy-lee.kehayes@dal.ca

The Caring Campus Toolkit is an integral part of the Caring Campus Project. The Toolkit can be accessed at https://doi.org/10.7870/ cjcmh-2018-018 


\author{
Sherry H. Stewart \\ Dalhousie University
}

\begin{abstract}
Alcohol intoxication is often involved for both victims and perpetrators of sexual victimization. Yet, alcohol-involved sexual victimization research has mainly focused on female victims, excluding male victims. The current study addresses gaps in the literature by focusing on sex differences in the emotional harms (anxiety and depression symptomatology) experienced by sexual victimization victims when either the perpetrator or victim was drinking. Five-hundred-and-ten undergraduate drinkers (153 male; 357 female) participated. Models included two dichotomized predictors that occurred during participants' first year of university (sexually victimized when the victim was drinking, sexually victimized by someone who was drinking), and two emotional outcomes (anxiety, depression). Age was controlled in all path analyses and sex was examined as a moderator. When predictors were examined in separate models, both predictors were associated with increased anxiety but not depression. These effects were significantly stronger among men. When both predictors were entered simultaneously, individuals who were victimized by someone drinking displayed increased anxiety, and this relationship was stronger among men than women victims. Being victimized when drinking was no longer associated with anxiety, consistent with prior findings that post-traumatic distress may be minimized when a trauma occurs while the victim is intoxicated. Results highlight the impact sexual victimization can have for both male and female victims, and point to the need for evidence-based policies to prevent emotional second-hand alcohol harms among male and female students alike.
\end{abstract}

Keywords: Sexual victimization; alcohol; second-hand harms; anxiety; depression.

\title{
RÉSUMÉ
}

L'intoxication à l'alcool est une situation souvent présente chez les victimes et les auteurs de victimisation sexuelle. Pourtant, à ce jour, les recherches sur la victimisation sexuelle impliquant la consommation d'alcool ont essentiellement porté sur les sujets de sexe féminin en négligeant les victimes masculines. La présente étude vise à combler les lacunes de la littérature existante en mettant l'accent sur les différences observées entre les sexes en ce qui concerne les préjudices émotionnels (symptomatologie anxieuse et dépressive) subis par les victimes d'agressions sexuelles lorsque l'auteur ou la personne agressée était sous l'effet d'alcool. Cinq cent dix buveurs de premier cycle (153 hommes et 357 femmes) ont participé à l'étude. Les modèles retenus comprenaient deux prédicteurs dichotomisés survenus lors de la première année universitaire des participants (violences sexuelles à l'égard d'une victime qui était sous l'effet de l'alcool et violences sexuelles commises par un agresseur qui était sous l'effet de l'alcool) et deux états émotionnels (l'anxiété et la dépression). L'âge a fait l'objet d'un contrôle dans l'ensemble des analyses de pistes causales, alors que le sexe fut examiné en tant qu'élément modérateur. Lorsqu'ils furent analysés dans le cadre de modèles distincts, les deux prédicteurs furent associés à une augmentation des troubles anxieux, mais non de la dépression. Cette relation s'est révélée nettement plus marquée chez les victimes de sexe masculin. Lorsque les deux prédicteurs ont été saisis simultanément, les personnes victimisées par un agresseur qui était sous l'effet de l'alcool ont affiché un niveau accru d'anxiété, cette relation étant nettement plus manifeste chez les victimes masculines que féminines. Être victimisé tout en étant sous l'effet de l'alcool n'était plus une condition associée à l'émergence de l'anxiété, ce qui concordait avec les résultats d'études antérieures selon lesquelles la détresse post-traumatique peut se trouver atténuée lorsqu'un traumatisme survient alors que la victime est en état d'ébriété. Les résultats obtenus mettent en évidence l'incidence que la victimisation sexuelle peut avoir sur les victimes masculines et féminines, et soulignent 
la nécessité de la mise en place de politiques fondées sur des données probantes pour prévenir les méfaits émotionnels secondaires associés à l'intoxication à l'alcool chez les étudiants de sexe masculin et féminin.

Mots clés : victimisation sexuelle; alcool; méfaits secondaires; anxiété; dépression.

Sexual violence is a human rights, public health, and sex-based issue (Basile, Hall, \& Walters, 2013). To date, research on its various forms - childhood sexual abuse, sexual assault, sexual harassment, sexual coercion in dating violence, and sexual exploitation - has mainly focused on adults and female victims (Grayson \& Nolen-Hoeksema, 2005; White \& Widom, 2008). A sizeable knowledge gap exists regarding health outcomes in male youth who have been victimized. The sexual violence victimization of young men is a critical research priority given (1) the scope of the problem, and (2) the lack of knowledge about malespecific impairment patterns (e.g., Collin-Vézina, Daigneault, \& Hébert, 2013; Finkelhor, Shattuck, Turner, \& Hamby, 2014). The present study helped to close these gaps in the literature by focusing on the consequences of sexual victimization to mental health in both female and male college students. Secondly, the present study investigated the role of alcohol use in sexual victimization by assessing the effects of victimization when either the perpetrator or the victim was intoxicated, permitting a comparison of the emotional consequences of both forms of alcohol-involved sexual victimization.

Sexual victimization is defined as non-consensual sexual contact, ranging from harassment (i.e., verbal or non-verbal remarks experienced as unwanted or offensive) to physical touching and penetration. All of these non-consensual sexual contacts are considered forms of victimization and can have negative impacts on college students' health and well-being (Paludi, Nydegger, DeSouza, Nydegger, \& Dicker, 2006). Approximately $20 \%$ of women experience more severe forms of sexual victimization (i.e., sexual assault) while attending college (Krebs et al., 2011), whereas rates of sexual victimization in college men are typically lower, with estimates ranging from 1-14\% (Aizenman \& Kelley, 1988; Baier, Rosenzweig, \& Whipple, 1991). Sexual victimization rates in males may be underestimated, however, as males may be more reluctant to disclose sexual violence (Collin-Vézina et al., 2013). Indeed, some research suggests that rates of sexual coercion on college campuses are similar for both male and female students (Larimer, Lydum, Anderson, \& Turner, 1999). Due to the high rates of sexual victimization on campuses, researchers have examined risk factors associated with sexual victimization (McDermott, Kilmartin, McKelvey, \& Kridel, 2015).

One of the most heavily researched risk factors is alcohol use. Sexual victimization and alcohol use often co-occur, with 50-70\% of sexual victimizations involving the use of alcohol (Reed, Amaro, Matsumoto, \& Kaysen, 2009). Women who drink alcohol regularly are more likely to be sexually victimized than women who do not drink or those who do not drink regularly (Testa \& Livingston, 2000; Tyler, Schmitz, \& Adams, 2015), and this risk increases with heavy drinking behaviour (Abbey, Zawacki, Buck, Clinton, \& McAuslan, 2004). Further, alcohol may interfere with the victim's ability to keep him or herself safe due to intoxicationrelated cognitive impairments. For example, intoxication may make it more difficult to recognize and respond to dangerous situations, contributing to the likelihood of sexual victimization (Davis, Stoner, Norris, George, $\&$ Masters, 2009). This is not to suggest that a victim who has been drinking is at fault, as the responsibility clearly lies with the perpetrator. 
Alcohol use is also commonly observed in sexual victimization perpetrators. One study estimated that $47 \%$ of college perpetrators consumed alcohol at the time of an assault (Abbey, McAuslan, \& Ross, 1998). Perpetrators may drink alcohol purposefully before an assault to enable or justify their planned behaviour (Zinzow \& Thompson, 2015). Conversely, personality characteristics such as narcissism, impulsivity, sensation-seeking, or life experiences such as childhood maltreatment or adolescent sexual assault, may lead perpetrators to drink heavily and then to sexually victimize others (Abbey et al., 2004; Wegner \& Abbey, 2016). Additionally, individuals who are predisposed to sexually victimize may be more likely to act on their desires when drinking due to alcohol's effects on higher-order cognitive processes such as planning, decision-making, and inhibition (Wegner \& Abbey, 2016). Beliefs about alcohol's effects on sexual arousal may also be important contributors to sexual victimization. In a study by George, Stoner, Norris, Lopez, and Lehman (2000), college men who thought they were drinking alcohol were more sexually aroused by depictions of both consensual and forced sex than men who did not think they had consumed alcohol, pointing to the important role of alcohol expectancies in men's sexual arousal.

Sexual victimization often leads to increases in internalized distress such as depression, anxiety, and post-traumatic stress responses in women (Ullman \& Najdowski, 2010), and increases in externalizing behaviours, such as drinking and drug use (Najdowski, \& Ullman, 2009). It is often assumed that men suffer fewer negative consequences from sexual victimization (Peterson, Voller, Polusny, \& Murdoch, 2011). This may be a result of societal beliefs suggesting that men cannot be sexually victimized, and that male sexual victimization rarely happens (Hodge \& Canter, 1998). While some research suggests that men do suffer fewer negative consequences after sexual victimization (e.g., Banyard et al., 2007), other studies report similar anxiety, depression, anger, and alcohol abuse consequences for both sexes (Heidt, Marx, \& Gold, 2005). Given these conflicting findings, and the paucity of research on the emotional effects of sexual victimization in young men, more research is needed.

The present study investigated the consequences of sexual victimization on emotional health in men and women college students who were drinking at the time they were victimized. Due to the high rates of both alcohol use and sexual victimization on college campuses (Buchholz, 2015), it is important to examine how these two factors intersect and negatively impact student victims' emotional health. Further, the World Health Organization (2010) has identified harm from others' drinking as one of four priority research areas. Thus, another study aim was to investigate the emotional consequences of sexual victimization by someone who was drinking at the time they victimized someone, through comparison of the emotional health outcomes of being intoxicated when victimized versus when the perpetrator was intoxicated. Gaps in the sexual victimization literature were addressed by a dual focus on the harms associated with one's own drinking and the harms resulting from others' drinking. Anxious arousal (i.e., hyperarousal and somatic tension) and anhedonic depression (i.e., low energy and loss of pleasure in activities) were examined as potential outcomes of both types of alcohol-involved sexual victimization as both emotional consequences have been linked to sexual violence exposure in previous literature (Peterson et al., 2011). Arousal and hypervigilance, as well as anhedonia and dysphoria, are also common symptoms of post-traumatic stress disorder (American Psychiatric Association, 2013) and are theoretically relevant outcomes in post-traumatic stress models (e.g., Frewen \& Lanius, 2015). It was hypothesized that both men and women college students who experienced sexual victimization while intoxicated or who were sexually victimized by an intoxicated perpetrator would 
report significantly more anxiety and depression symptoms than college students who did not report alcoholinvolved sexual victimization experiences.

\section{METHOD}

\section{Participants}

Participants were 819 first-year undergraduate students attending an eastern Canadian post-secondary institution. Participants' mean age was $18.3(S D=1.9)$ years; $69.1 \%$ were female and $89.9 \%$ were Canadian students. In terms of drinking behaviour, $17.9 \%$ reported drinking five or six drinks on a typical drinking occasion, and $17 \%$ reported weekly binge drinking episodes (i.e., drinking four or more drinks for women or five or more drinks for men during a single occasion).

\section{Measures}

Alcohol use over the past term. Participants were asked "How would you describe your alcoholdrinking pattern this term?" Response options were "abstainer," "occasional," "light," "moderate," and "heavy." Participants were then included in the study if they indicated any alcohol use, regardless of severity.

Alcohol-involved sexual victimization - drinking by victim. To measure personal harms associated with alcohol use, participants were asked "How often have you experienced the following as a result of using alcohol this term?" Students then responded to potential harms (e.g., got nauseated or vomited; damaged property). The item of interest for the present study was whether the participant "was taken advantage of sexually." Response options were "never," "once or twice," "3-5 times," "6-10 times," or "more than 10 times." Because the distribution of scores was positively skewed, responses were recoded dichotomously into 0 ("not sexually victimized while drinking") or 1 ("sexually victimized while drinking”).

Alcohol-involved sexual victimization-drinking by perpetrator. The second-hand harms of alcohol/drug use were assessed with the question "How many times this term has another student (i.e., friend, roommate, classmate, or other student) who had been drinking or using drugs ..." Students then responded to possible second-hand harms (e.g., stressed you out, interrupted your studies). The item of interest was whether another student who had been drinking/using drugs had "sexually harassed or sexually assaulted you." Response options were "never," “once or twice," "three or more times," or "five or more times." Due to positive skew, responses were recoded dichotomously into 0 ("not sexually victimized by someone who was drinking") or 1 ("sexually victimized by someone who was drinking").

Anxious arousal and anhedonic depression. The Mood and Anxiety Symptoms Questionnaire (MASQ; Watson et al., 1995) is a 77-item self-report questionnaire used to measure depressive, anxious, and mixed symptomatology. The 38 items from the MASQ that measure symptoms of "anhedonic depression" and "anxious arousal" were administered in the present study (hereafter referred to as "depression" and "anxiety," respectively). Participants reported the extent to which they felt each emotional symptom during the last 30 days on a five-point Likert scale ranging from 1 ("not at all") to 5 ("extremely"). Twentyone items assessed depression-specific symptoms such as loss of pleasure in usual activities ("depression") and 17 items assessed somatic tension and hyperarousal ("anxiety"). Items were summed to create two 
subscales. Depression scores could range from 21-105 and anxiety scores could range from 17-85. The MASQ subscales have good internal consistency ( $\alpha$ s $\geq .85$ ) and demonstrate convergent validity with both the Beck Depression Inventory and the Profile of Mood States (Watson et al., 1995). Both scales showed good-to-excellent internal consistency in the present sample (depression $\alpha=.80$; anxiety $\alpha=.92$ ).

\section{Procedure}

Study procedures were approved by a university research ethics board. All first-year undergraduates were invited to participate via email. Reminder emails were sent out once a week for three weeks until data collection was complete. On-campus posters, newsletters, and social media advertisements about the survey were also used in recruitment. The response rate from first-year students was $32 \%$, similar to other Canadian undergraduate surveys (e.g., American College Health Association, 2013). The survey took approximately 30 minutes to complete and participation was voluntary. The survey included various questionnaires that focused on patterns of substance use with a particular focus on alcohol, emotional health, reasons for drinking, personality, substance-related harms, and perceptions of campus drinking culture. Only those measures directly pertinent to this study are described in this paper. Participants were compensated in the form of gift cards or course credit, or they could donate the cash value of their gift card to support mental health promotion and alcohol harm reduction activities on campus.

\section{Data Analytic Procedure}

To be included in analyses, participants had to be a "drinker" (i.e., any category but "abstainer") since the first sexual victimization predictor (sexual victimization while drinking) requires that the victim drinks alcohol. The second sexual victimization predictor (being victimized by someone who was drinking) did not require participants to be drinkers themselves. Nonetheless, non-drinkers were excluded from all analyses to ensure that the same participants were included in all analyses so that direct comparisons could be made between models. Two participants identified their sex as "other" and were excluded from analyses since they could not be included in comparisons across sex. These restrictions resulted in an overall sample size of 510 participants (357 women; 153 men).

Path analyses were used to examine the associations between two types of alcohol-involved sexual victimization (sexually victimized when drinking alcohol; sexually victimized by a drinking perpetrator) and two emotional health consequences (anxiety; depression). Each predictor was modelled separately with both consequences, and then combined into a single model with both predictors and both consequences. Models controlled for age and were just-identified, so no fit indices are reported. The moderating effect of sex was also assessed using a multiple-groups model that compared changes in model fit resulting from imposing and releasing equality constraints on model parameters across sex (Bollen \& Curran, 2006), and tested by a chi-square statistic. All analyses were conducted with MPlus 7.11. 
Table 1

Prevalence of Sexual Victimization

\begin{tabular}{llll}
\hline & & Sex \\
\hline Sexual Victimization Items & Total & Female & Male \\
& $N=510$ & $n=357$ & $n=153$ \\
\hline Sexual victimization by intoxicated perpetrator & $11.9 \%$ & $13.4 \%$ & $8.5 \%$ \\
Sexual victimization of intoxicated victim & $8.8 \%$ & $10.4 \%$ & $6.8 \%$ \\
\hline
\end{tabular}

Note. No significant chi-square difference tests were observed between men and women.

Table 2

Point-Biserial Correlations among Variables

\begin{tabular}{|c|c|c|c|c|}
\hline & 1 & 2 & 3 & 4 \\
\hline \multicolumn{5}{|l|}{ Male $(n=153)$} \\
\hline 1. SVIP & - & $.64[.34, .86]$ & $.18[.08, .29]$ & $.34[.15, .52]$ \\
\hline 2. SVIV & & - & $.13[.04, .23]$ & $.25[.05, .45]$ \\
\hline 3. Anhedonic Depression & & & - & $.26[.11, .40]$ \\
\hline 4. Anxious Arousal & & & & - \\
\hline \multicolumn{5}{|l|}{ Female $(n=357)$} \\
\hline 1. SVIP & - & $.48[.32, .62]$ & $.02[-.07,12]$ & $.13[.02, .25]$ \\
\hline 2. SVIV & & - & $-.03[-.14, .07]$ & $.07[-.05, .19]$ \\
\hline 3. Anhedonic Depression & & & - & $.36[.27, .45]$ \\
\hline 4. Anxious Arousal & & & & - \\
\hline
\end{tabular}

Note. SVIP = Sexual victimization by intoxicated perpetrator. SVIV = Sexual victimization of intoxicated victim. Confidence intervals are based on 5,000 bootstrapped resamples. Bolded correlations are significant (i.e., do not contain zero within their confidence interval). 


\section{RESULTS}

\section{Missing Data and Descriptive Statistics}

Models containing the question asking participants if they were sexually victimized when intoxicated had slightly lower samples sizes than other models (488 versus 510 participants), as $4.7 \%$ of participants failed to answer this question. Of the total sample, $11.9 \%$ reported being sexually victimized by someone who was drinking, and $8.8 \%$ reported sexual victimization while intoxicated (see Table 1 ). Neither sex was more likely to experience sexual victimization when the perpetrator was drinking, $\chi^{2}(1)=2.491, p=.115$, or sexual victimization when intoxicated, $\chi^{2}(1)=1.586, p=.208$. As participants may have experienced both types of sexual victimization, a chi-square test was conducted that revealed that $6.0 \%$ of the sample experienced both types of sexual victimization, $\chi^{2}(1)=130.11, p<.001$. Correlational analyses (see Table 2) demonstrated that experiencing sexual victimization when the perpetrator was drinking was positively correlated with experiencing sexual victimization when the victim was drinking in both men and women. Experiencing sexual victimization when the perpetrator was drinking was positively correlated with both depression and anxiety for men, whereas this type of victimization was only related to anxiety for women. Experiencing sexual victimization when the victim was drinking was positively correlated with both depression and anxiety for men, whereas this type of victimization was unrelated to both emotional outcomes in women.

\section{Path Analyses}

Associations were examined between victim and perpetrator alcohol-involved sexual victimization and emotional consequences (see Figure 1). Individuals who were sexually victimized when drinking experienced significantly more anxiety, but not depression, than those who were not so victimized. Men who experienced sexual victimization when drinking experienced increased anxiety, whereas women did not. The association between experiencing sexual victimization when drinking and anxiety was significantly stronger for men than for women, $\Delta \chi^{2}(9)=47.52, \mathrm{p}<.001$.

Individuals who were sexually victimized by someone who was drinking experienced significantly more anxiety, but not depression, than those who were not so victimized (see Figure 1). Men who were sexually victimized by someone drinking experienced significantly more anxiety than males who were not so victimized. Women who were sexually victimized by someone drinking also experienced significantly more anxiety than women who were not so victimized. Men who were sexually victimized by someone who was drinking also experienced significantly more depression than men who were not so victimized; this effect was not seen in women. The association between being sexually victimized by someone who was drinking and both emotional outcomes was significantly stronger for men than for women, $\Delta \chi^{2}(9)=47.94, p<.001$.

Both alcohol-involved sexual victimization predictors were combined into a single model with both emotional consequences (see Figure 2). Individuals who were sexually victimized by someone drinking experienced significantly more anxiety, but not depression, than those who were not so victimized. Experiencing sexual victimization when drinking was no longer associated with either emotional consequence. Males who were sexually victimized by someone drinking experienced significantly more anxiety than individuals who were not so victimized. Women who were sexually victimized by someone drinking also experienced significantly more anxiety than women who were not so victimized. The association between being sexually 


\section{Figure 1}

\section{Path Analyses}

A)

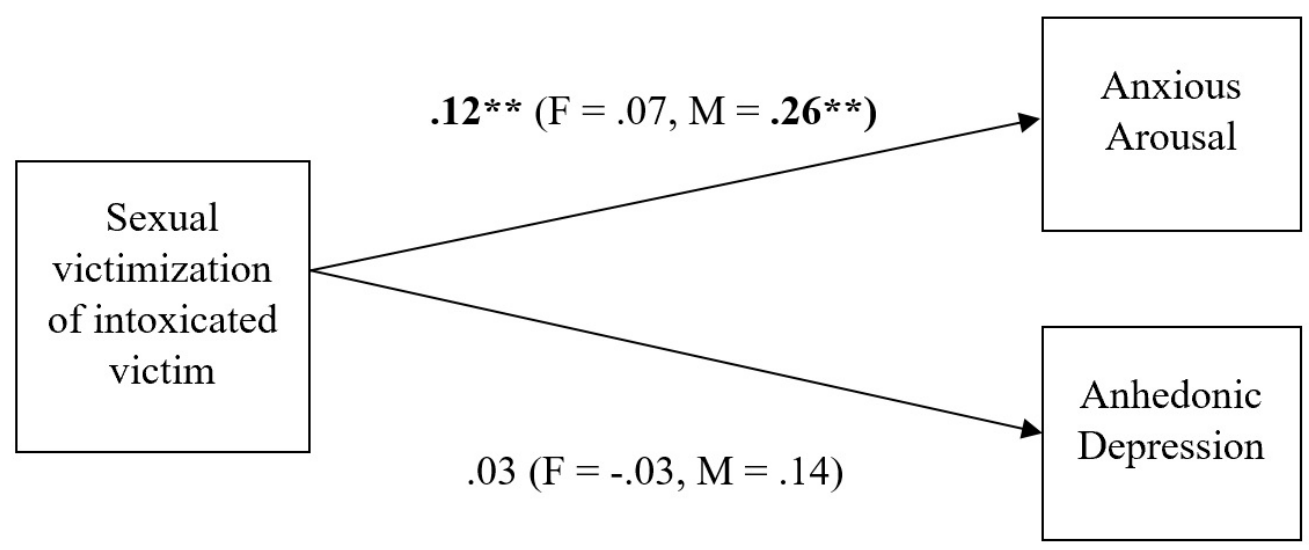

B)

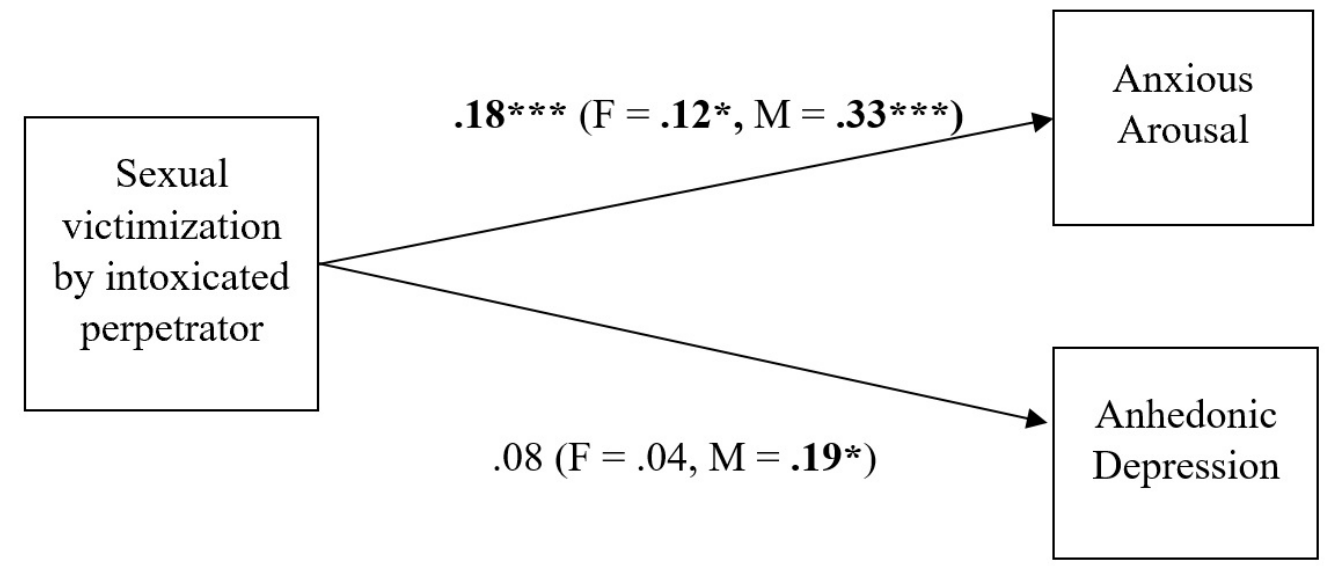

Notes: Path analysis results depict associations while controlling for age. Bolded coefficients indicate significant paths. Sex was tested as a moderator in both models, and separate path coefficients are depicted for each sex in parentheses. $\mathrm{F}$ = female model. $\mathrm{M}$ = male model. Both sex models were statistically different from each other in both analyses.

$* * * p<.001, * * p<.01, * p<.05$. 


\section{Figure 2}

\section{Combined Path Analysis}

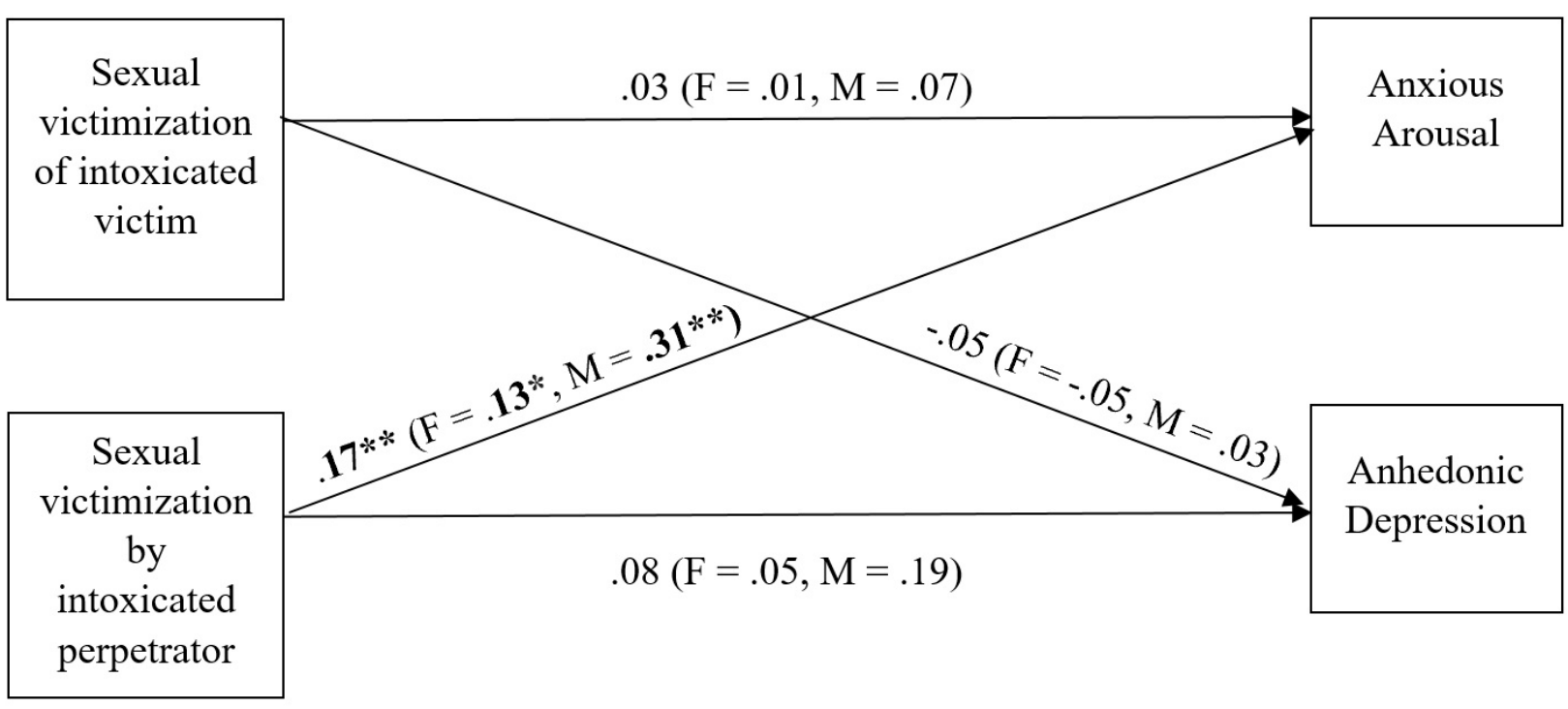

Notes: Path analysis results depict associations while controlling for age. Bolded coefficients indicate significant paths. Separate path coefficients are depicted for each sex in parentheses. $\mathrm{F}=$ female model. $\mathrm{M}=$ male model. Both sex models were statistically different from each other.

$* * * p<.001, * * p<.01, * p<.05$. 
victimized by someone who was drinking and anxiety was significantly stronger for men than for women, $\Delta \chi^{2}(11)=51.34, \mathrm{p}<.001$.

\section{DISCUSSION}

The present study examined the emotional consequences of alcohol-involved sexual victimization in both female and male university students. Similarly high rates of sexual victimization were reported by both men and women in the present study, which contributes to research focused on the rates and experiences of men who have been sexually victimized. Despite research that suggests a troubling prevalence of sexual victimization on campus among men as well as women, there continues to be a lack of research into the experiences of men who have been sexually victimized. This could be attributed to societal biases surrounding male victims of sexual victimization, driven by male rape myths that suggest men do not experience serious forms of non-consensual sexual contact (Turchik, 2012). As evidenced by the present study, it is critical to include both sexes in sexual victimization research as both sexes are unfortunately victimized at concerning rates on college campuses.

\section{Sexual Victimization and Emotional Outcomes}

When analyzed in separate models, alcohol use by the perpetrator and victim were associated with increased anxiety. However, when analyzed together, only alcohol use by the perpetrator was associated with increased anxiety. Prior literature suggests alcohol use by the assailant is associated with greater violence in the assault and injury to the victim (Abbey, 2002; Ullman, 2003). Thus, individuals who were sexually victimized by a drinking perpetrator may have experienced more violence than those who were intoxicated themselves, which may explain the former group's increased anxiety.

There was no association in the full model between intoxication in the victim during sexual victimization and increased anxiety. At first, this result seems counterintuitive as victim substance use during sexual victimization is associated with greater self-blame among individuals who have been sexually victimized (Koss, Figeuredo, \& Prince, 2002). Individuals who have been sexually victimized who were drinking or using drugs prior to their assault are also blamed more by others and seen as less credible reporters than victims who were not drinking or using drugs (Hammock \& Richardson, 1997). Given the high rates of selfblame among intoxicated victims and the negative responses from others, it would follow that victims who were drinking should experience more distress. However, alcohol and other drugs dampen physiological and emotional stress responses during traumatic events. Therefore, alcohol use by the victim at the time of assault may buffer the later emotional effects of the assault by inhibiting stress responding during the victimization (Sher, Bartholow, Peuser, Erickson, \& Wood, 2007). In fact, victims who report consuming alcohol prior to sexual victimization appraise their assault as less serious and experience fewer physical reactions compared to those who do not report drinking prior to being victimized (Clum, Nishith, \& Calhoun, 2002). Alcohol use prior to a sexual victimization may also interfere with the encoding, consolidation, or retrieval of traumatic memories, which could then influence symptoms such as intrusive memories (Maes, Delmeire, Mylle, \& Altamura, 2001), or anxiety, as seen in the current study. 
This study suggests that experiencing sexual victimization by a drinking perpetrator results in greater anxiety for the victim. While increased depression in men was noted post-victimization, this effect was smaller in magnitude than that seen for anxiety and was absent in the full model. This result may have been due to our specific measurement of anhedonic depression, as other studies have found associations using depressionrelated constructs such as hopelessness (e.g., Peterson et al., 2011). Anhedonic depression symptoms may be a feature of college students with a history of traumatic experiences, such as child maltreatment and, as such, may be most relevant to this sub-group (Frewen \& Lanius, 2015). The present study also examined short-term effects of sexual victimization. Anxiety responses may be more likely to occur shortly after victimization, whereas there may be a shift toward depressive symptoms over time. Further, there may be other important moderators between sexual victimization and depression, such as self-blame (Garnets, Herek, \& Levy, 1990), which were not measured in the present study. Perhaps alcohol-involved sexual victimization does not result in depression overall—only among those who blame themselves for the event.

\section{Sex Differences}

While both men and women experienced increased anxiety after sexual victimization by a perpetrator who was drinking, this relationship was stronger in men than women. Men in the current study may have been victimized more severely than women given that women are more likely to report sexual victimization of all types (McMullen, 1990). This may account for the more pronounced negative emotional responses found in men. Rape myths (e.g., responsibility of the victim) also contribute to negative consequences experienced post-assault. While much has been done to combat female rape myths (Edwards, Turchik, Dardis, Reynolds, \& Gidycz, 2011; Gidycz, Orchowski, \& Edwards, 2011), little attention has been paid to male rape myths (Davies, Gilston, \& Rogers, 2012). The internalization of male rape myths is associated with more self-blame and poorer outcomes after sexual victimization among men (Garnets et al., 1990). Males may also fail to report incidents of sexual victimization on surveys, even when their responses are anonymous. This may be related to the meaning of the event for the victim's sexual identity, depending whether the perpetrator was female or male. This may be particularly salient in environments, such as some college campuses, where ideals of masculinity are dominant for young men (Peterson et al., 2011; Turchik, 2012). Given these processes, sexually victimized men likely receive less social support than women, leading to consequences such as anxiety. In contrast, perceived social support increases the probability that the victim will share their distress with others, impacting their ability to cope and recover from the trauma (Chaudoir \& Fisher, 2010).

\section{Second-Hand Harms of Alcohol Use, Prevention, and Intervention}

The alcohol literature largely focuses on alcohol's effects on the individual, but investigation of secondhand harms of alcohol use has become a research priority (World Health Organization, 2010). The most common second-hand harms of alcohol that college students experience are being insulted or humiliated, having sleep or study interrupted, and having to "babysit" other intoxicated students (Rossow \& Hauge, 2004; Stiles, 2013; Thompson, Davis-MacNevin, Teehan, Stewart, \& The Caring Campus Research Team, 2017). In the present study, alcohol-involved sexual victimization by a perpetrator who had been drinking, a second-hand harm of alcohol use, was associated with increased anxiety in both men and women college 
students. As such, the results suggest that intervention efforts on campuses should target anxiety reduction in all those who have been sexually victimized regardless of the victim's sex.

Most universities have programs and policies in place to reduce second-hand harms from others' alcohol use. For example, bystander interventions are widely utilized across college campuses (Banyard, Moynihan, \& Plante, 2007; Vladutiu, Martin, \& Macy, 2011). These interventions aim to modify social norms, and to promote a community response that does not tolerate sexual violence. In these interventions, all students are considered bystanders to potential sexual violence and each student is assigned a role to reduce the occurrence of sexual violence. Some bystander intervention programs only train students how to reduce the sexual violence experienced by women (e.g., Vladutiu et al., 2011). The current results suggest the need for sex-inclusive sexual violence prevention intervention on college campuses. Further, preventative interventions should focus on intervening with intoxicated individuals who are potential perpetrators of sexual violence, as well as with potential victims.

\section{Limitations}

As in any study, certain limitations should be considered in the interpretation of the results. The current sample of Canadian first-year university students may limit the generalizability of the results to other emerging adult populations and different types of post-secondary students. Further, the present study employed only self-report questionnaires, which can be prone to social desirability effects (van de Mortel, 2008). However, all questionnaires were completed anonymously, which has been shown to produce more accurate estimations of sexual victimization rates (Fisher \& Cullen, 2000). We also excluded participants who did not respond to the sexual victimization items, and it is possible non-responders may have experienced a more severe assault and chose not to answer as a result. However, by using an anonymous survey this may have been minimized. Future research should attempt to engage hard to reach populations by ensuring anonymity and by appealing to their desire to help others in the future. The present study was also cross-sectional in design and thus cannot be used to determine causality. For example, anxiety may cause individuals to drink at social events (e.g., in order to cope with social anxiety) which could then place them at risk for victimization. Moreover, anxious individuals may be viewed by intoxicated perpetrators as "easy prey," providing an alternative explanation for the association between anxiety in the victim and sexual victimization by a perpetrator who had been drinking. The power to find effects was perhaps limited in the present study due to the relatively low incidence of sexual victimization. Further, the present study did not assess sexual victimization instances where alcohol was not involved, and did not measure the severity of reported sexual victimization instances. Future research should assess victimization severity, as it may influence mental health consequences (Abbey, 2002). Future studies should also directly compare alcohol-involved sexual victimization to non-alcohol-involved sexual victimization to determine whether alcohol involvement moderates the observed associations with emotional outcomes. Our sexual victimization questions were not specific when referring to the type of sexual victimization participants may have experienced. Future research should specifically separate sexual assault from sexual harassment. Our sexual victimization questions were also single items. We chose to use single items in the present study in order to reduce participant burden as this study was part of a larger project which included many other measures. Because our sexual victimization questions were not behaviourally explicit, this may have reduced reporting of sexual victimization. 
Furthermore, future sex-sensitive research should collect information about the sex of perpetrators relative to victims of sexual victimization to develop a fuller understanding of the nature of sexual victimization on campus and the potential meanings and impacts for victims. For example, a victim's emotional response to sexual victimization may vary depending on the sex of the perpetrator relative to their own sex and sexual orientation. Although we assessed aspects of emotional responses to sexual victimization, we did not assess post-traumatic stress disorder symptoms specifically or other important consequences such as sexual motives and sexual risk-taking (see Wekerle, Goldstein, Tanaka, \& Tonmyr, 2017); these represent interesting avenues for future research. While we measured anxiety and depression symptoms in the same term where the sexual victimization occurred, our outcome measures were not necessarily directly related to the occurrence of sexual victimization. In order to increase internal validity, future research could include covariates such as academic achievement and peer pressure. Our sexual perpetrator question also asked about intoxication due to alcohol or other drugs and thus was not specific to alcohol use, nor did it evaluate the amount of alcohol used. Future studies may choose to study specific intoxicants and query on dose for increased clarity. Finally, although we intended to ask about sexual victimization that occurred when an individual had been drinking, the wording chosen may have resulted in only those who perceived a link between their drinking and sexual victimization to respond (i.e., those who were more self-blaming). Future research should simply ask about the co-occurrence of these two behaviours (sexual victimization and alcohol use). Future research should also consider prospective designs to better study the emotional consequences caused by campus alcohol-involved sexual victimization.

\section{CONCLUSIONS}

Alcohol-involved sexual victimization on college campuses is a serious issue that affects both men and women. In our sample of first year students, perpetrator intoxication during sexual victimization was associated with increased anxiety in both sexes, with an even stronger association observed among men than women. Future research should continue to investigate sexual victimization consequences in both men and women college students to better understand the potentially different responses men and women have to sexual violence. Sexual violence intervention efforts on campuses should target both men and women and focus on reducing victims' anxiety. Further, alcohol policies and initiatives should focus on reducing emotional second-hand harms from drinking among men and women college students alike.

\section{REFERENCES}

Abbey, A. (2002). Alcohol-related sexual assault: A common problem among college students. Journal of Studies on Alcohol, Suppl. 14, 118-128. doi:10.15288/jsas.2002.s14.118

Abbey, A., McAuslan, P., \& Ross, L. T. (1998). Sexual assault perpetration by college men: The role of alcohol, misperception of sexual intent, and sexual beliefs and experiences. Journal of Social and Clinical Psychology, 17, 167-195. doi:10.1521/jscp.1998.17.2.167

Abbey, A., Zawacki, T., Buck, P., Clinton, A., \& McAuslan, P. (2004). Sexual assault and alcohol consumption: What do we know about their relationship and what types of research are still needed? Aggression and Violent Behavior, 9, 271-303.

American Psychiatric Association. (2013). Diagnostic and statistical manual of mental disorders: DSM-5. Washington, D.C: American Psychiatric Association. 
American College Health Association. (2013). American College Health Association-National College Health Assessment II: Canadian Reference Group Data Report Spring. Hanover, MD: American College Health Association.

Aizenman, M., \& Kelley, G. (1988). The incidence of violence and acquaintance rape in dating relationships among college men and women. Journal of College Student Development, 29, 305-311.

Baier, J. L., Rosenzweig, M., \& Whipple, E. (1991). Patterns of sexual behavior, coercion, and victimization of university students. Journal of College Student Development, 32, 310-322.

Banyard, V. L., Moynihan, M., \& Plante, E. (2007). Sexual violence prevention through bystander education: An experimental evaluation. Journal of Community Psychology, 35, 463-481.

Banyard, V. L., Ward, S., Cohn, E., Plante, E., Moorhead, C., \& Walsh, W. (2007). Unwanted sexual contact on campus: A comparison of women's and men's experiences. Violence and Victims, 22, 57-70. doi:10.1891/088667007780482865

Basile, K. C., Hall, J. E., \& Walters, M. L. (2013). Expanding resource theory and feminist-informed theory to explain intimate partner violence perpetration by court-ordered men. Violence against Women, 19, 848-880. doi: $10.1177 / 1077801213497105$

Bollen, K. A., \& Curran, P. J. (2006). Latent curve models: A structural equation perspective. New York: John Wiley $\&$ Sons.

Buchholz, L. (2015). The role of university health centers in intervention and prevention of campus sexual assault. Journal of the American Medical Association, 314, 438-440.

Chaudoir, S. R., \& Fisher, J. (2010). The disclosure processes model: Understanding disclosure decision-making and post disclosure outcomes among people living with a concealable stigmatized identity. Psychological Bulletin, 136, 236-256. doi: 10.1037/a0018193

Clum, G. A., Nishith, P., \& Calhoun, K. (2002). A preliminary investigation of alcohol use during trauma and peritraumatic reactions in female sexual assault victims. Journal of Traumatic Stress, 15, 321-328. doi:10.1023/A:1016255929315

Collin-Vézina, D., Daigneault, I., \& Hébert, M. (2013). Lessons learned from child sexual abuse research: Prevalence, outcomes, and preventive strategies. Child and Adolescent Psychiatry and Mental Health, 7, 1-9. doi:10.1186/1753-2000-7-22

Davies, M., Gilston, J., \& Rogers, P. (2012). Examining the relationship between male rape myth acceptance, female rape myth acceptance, victim blame, homophobia, gender roles, and ambivalent sexism. Journal of Interpersonal Violence, 27, 2807-2823. doi:10.1177/0886260512438281

Davis, K. C., Stoner, S. A., Norris, J., George, W., \& Masters, N. (2009). Women's awareness of and discomfort with sexual assault cues: Effects of alcohol consumption and relationship type. Violence against Women, 15, 1106-1125. doi:10.1177/1077801209340759

Edwards, K. M., Turchik, J., Dardis, C., Reynolds, N., \& Gidycz, C. A. (2011). Rape myths: History, individual and institutional-level presence, and implications for change. Sex Roles, 65, 761-773. doi:10.1007/s11199-011-9943-2

Finkelhor, D., Shattuck, A., Turner, H. A., \& Hamby, S. L. (2014). The lifetime prevalence of child sexual abuse and sexual assault assessed in late adolescence. Journal of Adolescent Health, 55, 329-333. doi:10.1016/j. jadohealth.2013.12.026

Fisher, B. S., \& Cullen, F. T. (2000). Measuring the sexual victimization of women: Evolution, current controversies, and future research. Criminal Justice, 4, 317-390.

Frewen, P., \& Lanius, R. (2015). Healing the traumatized self: Consciousness, neuroscience, treatment. New York, NY: Norton \& Co.

Garnets, L., Herek, G., \& Levy, B. (1990). Violence and victimization of lesbians and gay men: Mental health consequences. Journal of Interpersonal Violence, 5, 366-383.

George, W. H., Stoner, S. A., Norris, J., Lopez, P. A., \& Lehman, G. L. (2000). Alcohol expectancies and sexuality: A self-fulfilling prophecy analysis of dyadic perceptions and behavior. Journal of Studies on Alcohol, 61, 168-176.

Gidycz, C. A., Orchowski, L., \& Edwards, K. (2011). Primary prevention of sexual violence. In M. P. Koss, J. W. White, \& A. E. Kazdin (Eds.), Violence against women and children, Vol 2: Navigating solutions (pp. 159-179). Washington, DC: American Psychological Association. doi:10.1037/12308-008

Grayson, C. E., \& Nolen-Hoeksema, S. (2005). Motives to drink as mediators between childhood sexual assault and alcohol problems in adult women. Journal of Traumatic Stress, 18, 137-145. doi:10.1002/jts.20021

Hammock, G. S., \& Richardson, D. R. (1997). Perceptions of rape: The influence of closeness of relationship, intoxication, and sex of participant. Violence and Victims, 12, 237-246. 
Heidt, J. M., Marx, B., \& Gold, S. (2005). Sexual re-victimization among sexual minorities: A preliminary study. Journal of Traumatic Stress, 18, 533-540.

Hodge \& Canter. (1998). Victims and perpetrators of male sexual assault. Journal of International Violence, 13, 222-239.

Koss, M. P., Figueredo, A. J., \& Prince, R. J. (2002). Cognitive mediation of rape's mental, physical and social health impact: Tests of four models in cross-sectional data. Journal of Consulting and Clinical Psychology, 70, 926-941. doi:10.1037/0022-006X.70.4.926

Krebs, C. P., Lindquist, C. H., Warner, T. D., Fisher, B. S., Martin, S. L., \& Childers, J. M. (2011). Comparing sexual assault prevalence estimates obtained with direct and indirect questioning techniques. Violence against Women, $17,219-235$.

Larimer, M. E., Lydum, A. R., Anderson, B. K., \& Turner, A. P. (1999). Male and female recipients of unwanted sexual contact in a college student sample: Prevalence rates, alcohol use, and depression symptoms. Sex Roles, 40, 295-308. doi:10.1023/ A:1018807223378.

Maes, M., Delmeire, L., Mylle, J., \& Altamura, C. (2001). Risk and preventive factors of post-traumatic stress disorder (PTSD): Alcohol consumption and intoxication prior to a traumatic event diminishes the relative risk to develop PTSD in response to that trauma. Journal of Affective Disorders, 63, 113-121.

McDermott, R. C., Kilmartin, C., McKelvey, D. K., \& Kridel, M. M. (2015). College male sexual assault of women and the psychology of men: Past, present, and future directions for research. Psychology of Men \& Masculinity, 16, 355-366. doi:10.1037/a0039544

McMullen, R. (1990). Male rape: Breaking the silence on the last taboo. London: GMP Publishers.

Najdowski, C. J., \& Ullman, S. E. (2009). Prospective effects of sexual victimization on PTSD and problem drinking. Addictive Behaviors, 34, 965-968.

Paludi, M., Nydegger, R., DeSouza, E., Nydegger, L., \& Dicker, K. A. (2006). International perspectives on sexual harassment of college students. Annals of the New York Academy of Sciences, 1087, 103-120.

Peterson, Z. D., Voller, E. K., Polusny, M. A., \& Murdoch, M. (2011). Prevalence and consequences of adult sexual assault of men: Review of empirical findings and state of the literature. Clinical Psychology Review, 31, 1-24. doi:10.1016/j.cpr.2010.08.006

Reed, E., Amaro, H., Matsumoto, A., \& Kaysen, D. (2009). The relation between interpersonal violence and substance use among a sample of university students: Examination of the role of victim and perpetrator substance use. Addictive Behaviors, 34, 316-318. doi:10.1016/j.addbeh.2008.10.015

Rossow, I. \& Hauge, R. (2004). Who pays for the drinking? Characteristics of the extent and distribution of social harms from others' drinking. Addiction, 99, 1094-1102. doi:10.1111/j.1360-0443.2004.00788.x

Sher, K. J., Bartholow, B., Peuser, K., Erickson, D., \& Wood, M. (2007). Stress-response-dampening effects of alcohol: Attention as a mediator and moderator. Journal of Abnormal Psychology, 116, 362-377. doi:10.1037/0021-843X.116.2.362

Stiles, M. (2013). Second hand effects of substance use for rural college students. Journal of Human Behavior in the Social Environment, 23, 529-535. doi:10.1080/10911359.2013.765819

Testa, M., \& Livingston, J. (2000). Alcohol and sexual aggression: Reciprocal relationships over time in a sample of high-risk women. Journal of Interpersonal Violence, 15, 413-427.

Thompson, K., Davis-MacNevin, P., Teehan, M., Stewart, S., \& the Caring Campus Research Team. (2017). The association between second-hand harms from alcohol and mental health outcomes among postsecondary students. Journal of Studies on Alcohol and Drugs, 78, 70-78. doi:10.15288/jsad.2017.78.70

Tyler, K. A., Schmitz, R. M., \& Adams, S. A. (2015). Alcohol expectancy, drinking behavior, and sexual victimization among female and male college students. Journal of Interpersonal Violence, 8, 1-25. doi:10.1177/0886260515591280

Turchik, J. A. (2012). Sexual victimization among male college students: Assault severity, sexual functioning, and health risk behaviors. Psychology of Men and Masculinity, 13, 243-255. doi:10.1037/a0024605

Ullman, S. E. (2003). A critical review of field studies on the link of alcohol and adult sexual assault in women. Aggression and Violent Behavior, 8, 471-486. doi:10.1016/S1359-1789(03)00032-6

Ullman, S. E., \& Najdowski, C. (2010). Understanding alcohol-related sexual assaults: Characteristics and consequences. Violence and Victims, 25, 29-44.

van de Mortel, T. F. (2008). Faking it: Social desirability response bias in self-report research. Australian Journal of Advanced Nursing, 25, 40-48. 
Vladutiu, C. J., Martin, S., \& Macy, R. (2011). College or university-based sexual assault prevention programs: A review of program outcomes, characteristics, and recommendations. Trauma, Violence, and Abuse, 12, 67-86. doi: $10.1177 / 1524838090708$

Watson, D., Weber, K., Assenheimer, J. S., Clark, L. A., Strauss, M. E., \& McCormick, R. A. (1995). Testing a tripartite model: I. Evaluating the convergent and discriminant validity of anxiety and depression symptom scales. Journal of Abnormal Psychology, 104, 3-14. doi:10.1037/0021-843X.104.1.3

Wegner, R., \& Abbey, A. (2016). Individual differences in men's misperception of women's sexual intent: Application and extension of the confluence model. Personality and Individual Differences, 94, 16-20.

Wekerle, C., Goldstein, A. L., Tanaka, M., \& Tonmyr, L. (2017). Childhood sexual abuse, sexual motives, and adolescent sexual risk-taking among males and females receiving child welfare services. Child Abuse and Neglect, 66, 101-111. doi:10.1016/j.chiabu.2017.01.013

White, H. R., \& Widom, C. S. (2008). Three potential mediators of the effects of child abuse and neglect on adulthood substance use among women. Journal of Studies on Alcohol and Drugs, 69, 337-347. doi:10.15288/ jsad.2008.69.337

World Health Organization. (2010). Global strategy to reduce the harmful use of alcohol. Geneva, Switzerland. Retrieved from www.who.int/substance_abuse/activities/gsrhua/en/

Zinzow, H. M., \& Thompson, M. (2015). Factors associated with use of verbally coercive, incapacitated, and forcible sexual assault tactics in a longitudinal study of college men. Aggressive Behavior, 41, 34-43. doi:10.1002/ab.21567 